\title{
Occurrence of Euphausia pacifica HANSEN (Crustacea: Euphausiacea) with Spermatophore in the Vicinity of Otsuchi, Northeastern Japan
}

\author{
Makoto Terazaki, ${ }^{* 1}$ Daiji Kitagawa, ${ }^{* 2}$ and Yoh Yamashita*1 \\ (Accepted February 14, 1986)
}

\begin{abstract}
Vertical distributions of Euphausia pacifica HANSEN were investigated in the vicinity of Otsuchi, the Sanriku coast of northeastern Japan, in the spring of 1981 and 1982. Many females with attached spermatophore and male with empty ejaculatory ducts were distributed below $100 \mathrm{~m}$ along Todogasaki Section and Ozaki Section despite no remarkable thermocline. Females with spermatophore were distributed below $15 \mathrm{~m}$ depth throughout the whole day at Stn. A located near the mouth of Otsuchi Bay. Females with spermatophore occupied $45.0 \%$ of the total number of females collected from Stn. A. Minimum body length of males with at least one empty ejaculatory duct and females with spermatophore was $14 \mathrm{~mm}$. Main breeding location of E. pacifica is the shallow waters near the coast and their copulation takes place in mid-water.
\end{abstract}

Euphausia pacifica is restricted to the northern North Pacific where it is sole representative of the genus Euphausia. It occurs across the southern part of the Bering Sea, the Sea of Okhotsk and the Sea of Japan. The southern limit of its distribution agrees with the $9.5^{\circ} \mathrm{C}$ isotherm at $200 \mathrm{~m}$ depth. E. pacifica occurs mainly above $300 \mathrm{~m}$ depth, frequently in deeper layers during the day, and moving near the surface at night. ${ }^{1,2}$ ) The daytime surface swarming of E. pacifica is well known and the commercial fishery for this species on the Sanriku and Joban coasts of northeastern Honshu was described by Odate. ${ }^{3)}$ Mating of $E$. pacifica is performed by transfer of spermatophore from male to female. Spermatophore transfer may be inferred by examining either male ejaculatory ducts or female thelycum. Biological characteristics of $E$. pacifica collected by the commercial catch were reported but knowledge is rare concerning females with a spermatophore. ${ }^{4-5)}$

In 1981 and 1982, many females with spermatophore were confirmed in the plankton samples collected from the vicinity of Otsuchi.

\section{Materials and Methods}

Euphausia pacifica was collected during two cruises made off Otsuchi of the Sanriku, by the R/V Iwate Maru, the Iwate Prefectural Fisheries Experimental Station, in 1981 and 1982. A MTD net, ${ }^{6)}$ with a mouth diameter of $56 \mathrm{~cm}$ and mesh aperture of $0.33 \mathrm{~mm}$, was simultaneously towed in 10 different strata; $0,30,50,75,100,200,300$, 400,500 and $600 \mathrm{~m}$ at Stns. $1-4$ off Todogasaki and Stns. 5-9 off Ozaki during the daytime on 17-18 April 1982 (Fig. 1). For the investigation of the diel vertical migration, 7 hauls with a MTD net were made over a period of about 24 hours in different strata; $0,5,15,30$ and $50 \mathrm{~m}$ on $23-24$ March 1981 at Stn. A ( $80 \mathrm{~m}$ in depth) located near the mouth of Otsuchi Bay. Depth of the net was estimated from the record of a Depth-Distance meter installed on the net. A flowmeter was mounted in the mouth part of each net to estimate the volume of water filtered. Water temperature was measured with a digital bathy-thermometer.

Plankton samples were preserved in $5 \%$ buffered formalin seawater solution immediately after collection. E. pacifica was picked out from the samples collected at all stations and sorted into males, females and larvae (furcilia stage). Body length (B.L.), from the tip of the rostrum to the apex of the telson, was measured. The numbers of females with spermatophore and males with empty ejaculatory ducts were counted.

\section{Results}

Vertical profiles of water temperature along Todogasaki Section (Stns. 1-4) and Ozaki Section (Stns. 5-9) are shown in Fig. 2. Southward

*1 Ocean Research Insitute, University of Tokyo, Nakano, Tokyo 164, Japan (寺崎 羬, 山下 洋: 東京大 学海洋研究所).

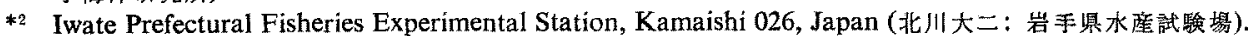




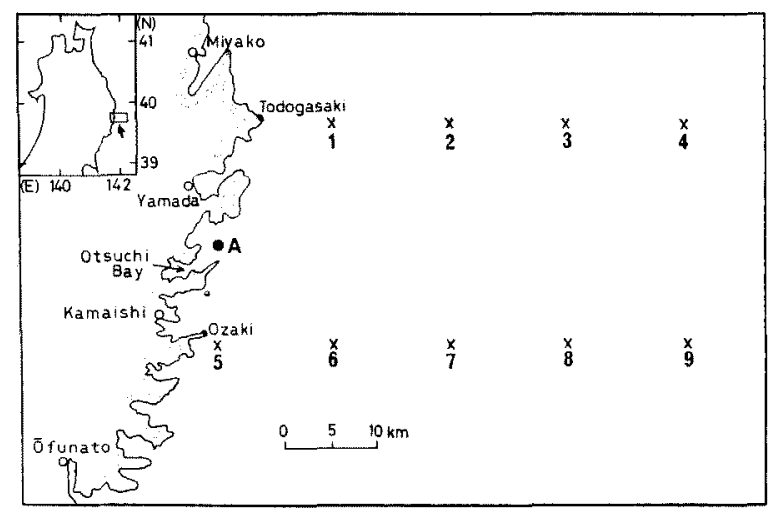

Fig. 1. Sampling stations. Stn. A (solid circle) was surveyed on 23-24 March 1981. Stns. 1-9 were surveyed on 17-18 April 1982.

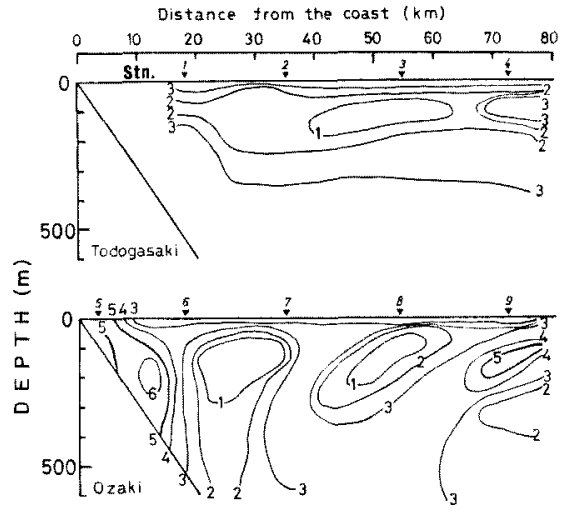

Fig. 2. Vertical profiles of water temperature along Todogasaki Section (Stns. 1-4) and Ozaki Section (Stns. 5-9)

expansion of the cold waters derived from the Oyashio Current was recognized beyond $20 \mathrm{~km}$ from the coastal shore in both sections. A remarkable front between coastal waters and cold Oyashio waters was formed about $15 \mathrm{~km}$ off Ozaki. Temperature from the surface to $80 \mathrm{~m}$ at Stn. A on 23-24 March 1981 was $5.8-5.1^{\circ} \mathrm{C}$.

No E. pacifica was collected from the surface at any station along the sections. Along Todogasaki Section, females were collected from Stns. 1-4 and males from Stns. 1-3, respectively. A few number of larvae occurred only at Stns. 1 and 2 (Fig. 3). Males with empty ejaculatory ducts were distributed below $100 \mathrm{~m}$ depth at Stns. 2 and 3. Females with spermatophore were mainly distributed in the $200-300 \mathrm{~m}$ layers at Stns. 1-4. In Ozaki Section, number of males, females and larvae decreased with increasing distance from the
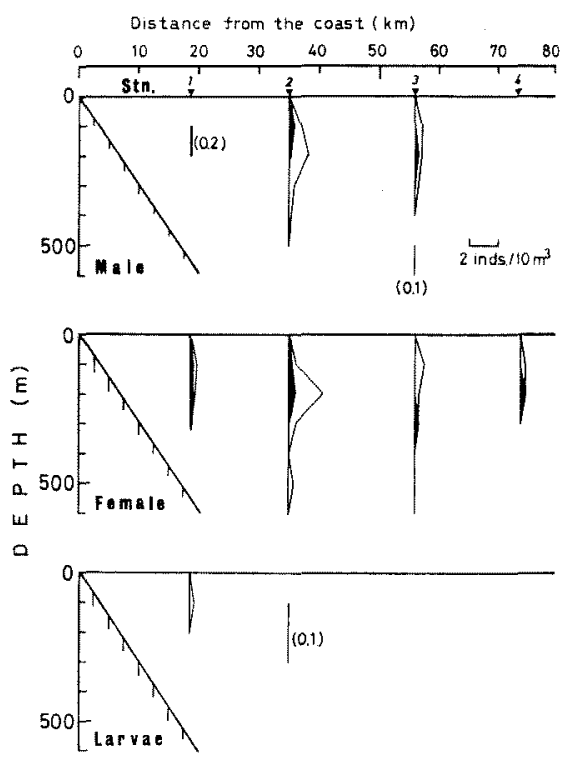

Fig. 3. Vertical distribution of males, females and larvae of Euphausia pacifica along Todogasaki Section. Shaded area represents the proportion of males with empty ejaculatory duct or females with spermatophore. Figures in brackets show number of individuals $/ 10 \mathrm{~m}^{3}$.

coast and no E. pacifica was found at Stn. 9 (Fig. 4). Males with empty ejaculatory ducts occurred at Stn. 5 and many females with spermatophore at Stns. 5-6. Males with empty ejaculatory ducts occupied $9.1 \%$ and $5.0 \%$ of the total number of males collected from Todogasaki Section and Ozaki Section. Females with spermatophore occupied $14.1 \%$ and $23.7 \%$, respectively (Table 1). 
Table 1. Mean body length (mm) and sex ratio of Euphausia pacifica collected from Todogasaki Section, Ozaki Section and Stn. A

\begin{tabular}{|c|c|c|c|c|c|}
\hline Sampling date & \multicolumn{2}{|c|}{ Sampling area } & $\underset{(\mathrm{m})}{\text { Sampling depth }}$ & No. & $\begin{array}{c}\text { Male (M) } \\
\text { Mean body length } \\
(\mathrm{mm})\end{array}$ \\
\hline March $23-24,1981$ & \multicolumn{2}{|c|}{ Stn. A } & $0-50$ & 46 & $15.2 \pm 1.4^{* 3}$ \\
\hline April 14-15, 1982 & \multicolumn{2}{|c|}{ Todogasaki Section } & $0-600$ & 48 & $15.6 \pm 2.1$ \\
\hline April 14-15, 1982 & \multicolumn{2}{|c|}{ Ozaki Section } & $0-600$ & 82 & $15.3 \pm 2.3$ \\
\hline Sampling date & No. & $\begin{array}{l}\text { Female }(F) \\
\text { Mean body length } \\
(\mathrm{mm})\end{array}$ & $\begin{array}{l}\text { Sex ratio } \\
(\mathrm{F} / \mathrm{M}+\mathrm{F})\end{array}$ & & $\begin{array}{l}B^{* 2} \\
(\%)\end{array}$ \\
\hline March $23-24,1981$ & 71 & $16.1 \pm 3.6$ & $60.7 \%$ & & 45.0 \\
\hline April 14-15, 1982 & 71 & $16.4 \pm 2.5$ & $59.7 \%$ & & 14.1 \\
\hline April $14-15,1982$ & 93 & $15.7 \pm 2.6$ & $53.1 \%$ & & 23.7 \\
\hline
\end{tabular}

*1 Male with at least one empty ejaculatory duct/total individuals of male.

*2 Female with spermatophore/total individuals of female.

* Standard deviation.
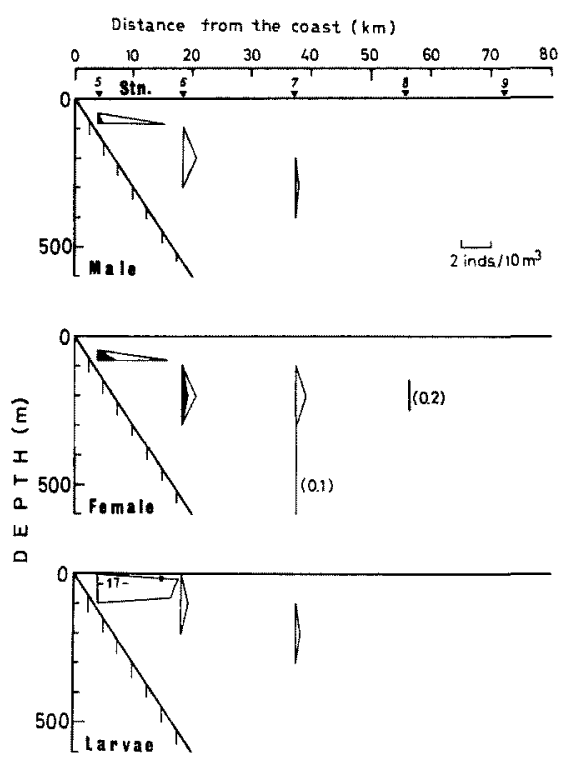

Fig. 4. Vertical distribution of males, females and larvae of Euphausia pacifica along Ozaki Section. Shaded area represents the proportion of males with empty ejaculatory duct or females with spermatophore. Figures in the brackets show number of individuals $/ 10 \mathrm{~m}^{3}$.

The vertical migrations of males, females and larvae were examined separately. Their behaviour was not necessarily similar. Males were distributed in the mid-water at or below $30 \mathrm{~m}$ depth during the day and migrated to a 5-15 m layer after sunset. Males with empty ejaculatory ducts occurred at $15 \mathrm{~m}$ depth at about $0200 \mathrm{~h}$ (Fig. 5). Generally, the majority of females showed a
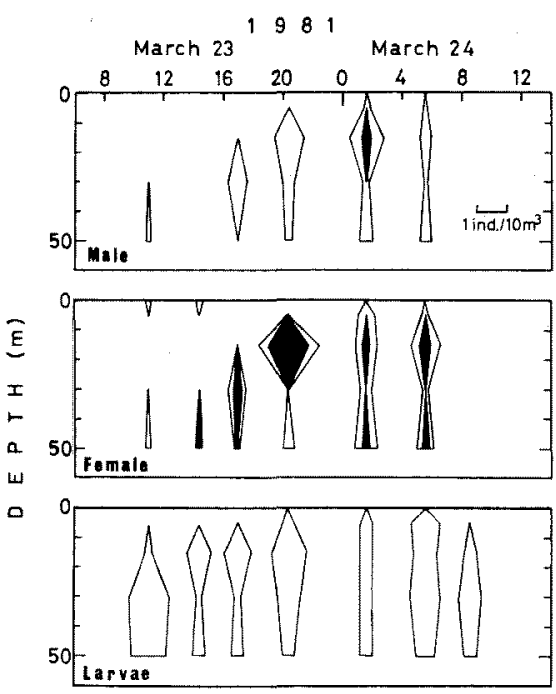

Fig. 5. Diel variation in the vertical distribution of males, females and larvae of Euphausia pacifica at Stn. A on 23-24 March 1981. Shaded area represents the proportion of males with empty ejaculatory duct or females with spermatophore.

similar migration pattern with males, but some females were collected from the surface during the daytime. Many females with spermatophore were distributed below $15 \mathrm{~m}$ depth throughout the whole day No larvae were collected from the surface and a remarkable diel migration of larvae was not observed in the present examination. Males with empty ejaculatory ducts occupied $6.5 \%$ of the total number of males collected from Stn. A. Females with spermatophore occupied $45.0 \%$. In the present observations, a large part of all 
specimens of E. pacifica was composed of mature individuals of $15-20 \mathrm{~mm}$ B.L. and generally, the mean body length of females is larger than that of males. Minimum body length of males with at least one empty ejaculatory duct and females with spermatophore was $14 \mathrm{~mm}$. The ratio of female to male ranged from $53.1 \%$ to $60.7 \%$ with a mean of $57.8 \%$.

\section{Discussion}

Komaki ${ }^{4)}$ reported many males with empty ejaculatory ducts in the samples which were landed at the Onagawa Fish Market, from the end of March to the beginning of May 1957, but no females with spermatophore were found. Endo ${ }^{5)}$ collected 22 samples every 2 or 3 days from March 3 to April 20, 1978 from the commercial catch landed at the Onagawa Fish Market and examined a total of 1048 females who had almost mature ovarian eggs. Only $1 \%$ of these females were found to have a spermatophore in their thelycum. Furthermore, these females occurred mainly in the sample collected on April 20. More than $60 \%$ of the males examined had at least one empty ejaculatory duct in the period from April 6 to April 11, 1978. Terazaki ${ }^{7)}$ observed a daytime surface swarm in Otsuchi Bay, and reported that there were no females with spermatophore in the swarm but some of the males held fully formed and undischarged spermatophores at the distal end of the ejaculatory ducts. Underwater observation on surface swarms of E. pacifica carried out by SCUBA diving in Sendai Bay on 27 March 1983 made clear that spermatophores of males were fully developed, but no females with spermatophore were observed. ${ }^{8)}$

Many females with spermatophore were collected by day and by night at $\mathrm{Stn}$. $\mathrm{A}$ and they were distributed below $15 \mathrm{~m}$ depth throughout the whole day. In the local commercial fishery, fishermen scoop E. pacifica swarms at the surface layer (upper $15 \mathrm{~m}$ ) with a pyramid-shaped net $(3 \times 2.5 \mathrm{~mm}$ mesh) and they never operate after sunset. Therefore, it is very difficult to catch females with spermatophore by this fishing method as they live in the mid-water below $15 \mathrm{~m}$. Occurrences of many males with empty ejaculatory ducts, females with spermatophore and larvae during the present survey probably indicate that spring is the breeding season in the vicinity of Otsuchi, Sanriku. Larvae decreased in number with distance from the coast and were not found at Stns. 3, 4, 8 and 9, while, high density of larvae was observed at Stn. 5 along Ozaki Section. These facts suggest that the main breeding location of E. pacifica is the shallow water near the coast.

\section{Acknowledgements}

The authors wish to express their thanks to the captain and crew of the $R / V$ Iwate Maru, the Iwate Prefectural Fisheries Experimental Station, for their cooperation in the collection of samples. Thanks are also due to Mr. Erik Thuesen, Ocean Research Institute, University of Tokyo for his reading of the manuscript. This work was supported in part by a Grant from the Ministry of Education, Science and Culture.

\section{References}

1) E. Brinton: Bull. Scripps Inst. Oceanogr., 8, 51270 (1962).

2) T. Nemoto: J. Oceanogr. Soc. Japan, 20th Ann. Vol., 615-627 (1962).

3) K. Odate: Bull. Tohoku Reg. Fish, Res. Lab., 40, 15-25 (1979).

4) Y. Komaki: Pac. Sci., 21, 433-448 (1967).

5) Y. Endo: Mar. Biol., 79, 269-276 (1984).

6) S. Motoda: Bull. Fac. Fish. Hokkaido Univ., 22, 101-106 (1971).

7) M. Terazaki: Bull. Plankton Soc. Japan, 27, 1925 (1980).

8) Y. Hanamura, Y. Endo, and A. Taniguchi: $L a$ mer, 22, 63-68 (1984). 